\title{
Properties of IRRAdiATEd PolyPROPYLENE
}

\author{
MANAS, D.; MANAS, M. \& STANEK, M.
}

Abstract: Radiation processing involves the use of natural or man-made sources of high energy radiation on an industrial scale. The principle of the radiation processing is the ability of the high energy radiation to produce reactive cations, anions, and free radicals in materials. The industrial application of the radiation processing of plastic and composites includes polymerization, cross-linking, degradation and grafting. Radiation processing involves mainly the use of either electron beams from electron accelerators or gamma radiation from Cobalt-60 sources. Radiation processing does not make the product radioactive. The majority of industrial applications of radiation processing are a cross-linking of wire and cable insulations, tube, heat shrink cables, components of tires, composites, moulded products for automotive and electrical industry etc. A comparison of the mechanical and thermal properties of natural and irradiated polypropylene (unfilled and filled $25 \%$ GF) is presented in this article.

Key words: Polymer, Irradiation, Crosslinking, Properties, Polypropylene
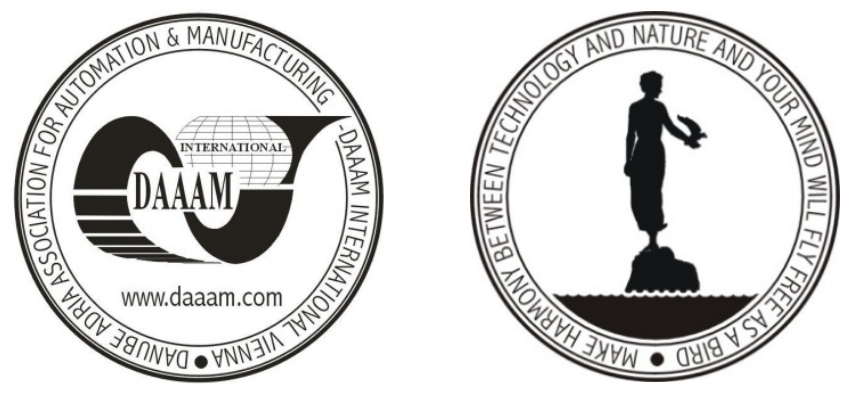

Authors' data: Dr. Manas, D[avid]; Manas, M[iroslav]; Dr. Stanek, M[ichal], Tomas Bata University in Zlin, TGM 275, 76272, Zlin, CZ, dmanas@ft.utb.cz, stanek@ft.utb.cz

This Publication has to be referred as: Manas, D[avid]; Manas, M[iroslav] \& Stanek, M[ichal] (2008). Properties of Irradiated Polypropylene, Chapter 37 in DAAAM International Scientific Book 2008, pp. 433-448, B. Katalinic (Ed.), Published by DAAAM International, ISBN 978-3-901509-66-7, ISSN 1726-9687, Vienna, Austria

DOI: $10.2507 /$ daaam.scibook.2008.37 